Machaj Dominik, Cyboran Katarzyna, Placzek Alicja, Baran Marlena, Wojnowski Michał. Opinions of physical education teachers about the preparation of teachers of early school education to carry out physical activities in classes I-III. Journal of Education, Health and Sport. 2020;10(5):118-122. eISSN 2391-8306. DOI http://dx.doi.org/10.12775/JEHS.2020.10.05.011

https://apcz.umk.pl/czasopisma/index.php/JEHS/article/view/JEHS.2020.10.05.011

https://zenodo.org/record/3827946

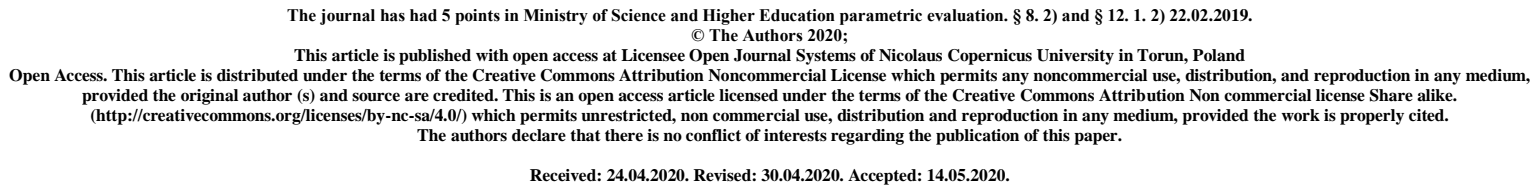

\title{
The importance of vitamin D3 supplementation in orthopedics - literature
} review

\author{
Dominik Machaj, Katarzyna Cyboran, Alicja Placzek, Marlena Baran, \\ Michał Wojnowski
}

Dominik Machaj dominik5a4@tlen.pl Faculty of Medicine, Medical University of Lublin, Chodźki Street 19, 20-093 Lublin Poland

Katarzyna Cyboran katarzyna_cyboran@o2.pl Medical Faculty, Institute of Medical Sciences, Collegium Medicum, Oleska Street 48, 45-052 Opole Poland

Alicja Płaczek alicja60@poczta.onet.pl Medical Faculty, University of Rzeszow, Pigonia Street 6, 35-310 Rzeszow Poland

Marlena Baran mbaran96@gmail.com Medical Faculty, University of Rzeszow, Pigonia Street 6, 35-310 Rzeszow Poland

Michał Wojnowski wojnowski.micha120@gmail.com Medical Faculty, University of Rzeszow, Pigonia Street 6, 35-310 Rzeszow Poland 


\section{Summary}

Falls have been recognized by the WHO as one of the most significant problems in aging societies. In the elderly after 65 years of age, they cause $90 \%$ of the fractures of the proximal femoral bone (bkk) and 100\% of the forearm fractures [5].They usually occur when walking (most often), getting up and sitting down. The consequences of falls, as well as themselves, can be prevented by supplementing vitamin D3 [6] [8] regulating the body's calciumphosphate homeostasis. It improves neuromuscular function, including the mechanism reduces the frequency of falls. It also affects response time and balance. The concentration of vitamin D3 in the body is variable. Depends on endogenous biosynthesis and food supply. It also shows seasonal fluctuations. Its deficiencies lead to not only orthopedic and dental complications. It has been proven that there is a decreased level of $25(\mathrm{OH}) \mathrm{D} 3$ in serum and such diseases as diabetes, hypertension, depression,neuro-degenerative diseases including Alzheimer's disease and increased likelihood of cancer, especially breast, prostate, and colon cancers [15].

\section{Key words: vitamin D3, orthopedics, fractures, falls}

\section{INTRODUCTION AND PURPOSE}

Vitamin D3 is a regulatory compound associated mainly with the absorption of calcium and phosphorus from the gastrointestinal tract and in the kidneys, as well as maintaining homeostasis of the mineral economy. Its primary use has been the treatment and prevention of rickets in children and osteomalacia in adults, which leads to increased bone fragility. The correct concentration of vitamin D3 in the blood determines the proper functioning and mechanical strength of the skeleton. Calcitriol (1,25-dihydroxycholecalciferol) is a hormonally active form of vitamin D3, which due to its action belongs to the group of steroid hormones which are transcription factors of target protein genes acting on the intracellular, highly specific receptor of VDR [1]. The active form of vitamin D3 is formed by hydroxylation of vitamin D3 at position 25 in the liver by 25-hydroxycalciferol hydroxylase and at position 1 in the kidneys. Vitamin D deficiency afflicts over one billion children and adults over the world. Its deficiency results not only in diseases associated with bone demineralization. Vitamin D deficiency is connected with neurological disorders, cardiovascular disease, autoimmune disorders, infectious diseases, preeclampsia, childhood dental caries, periodontitis, type 2 diabetes and even deadly cancers [2]. The effect of vitamin $\mathrm{D}$ on diseases in which proliferative disorders, cell differentiation and apoptosis occurs suggests the possibility of using it in the treatment of these diseases. The discovery of antiproliferative and inducing leukemia cell differentiation in vitro has led to a renewed interest in calcitriol. It has been shown to inhibit cell division of the reproductive layer of the epidermis in psoriasis [3], as well as to induce cell differentiation of head and neck, breast, prostate and colorectal cancers [4]. This review aims to gather the results of studies on the biological activity of vitamin D, the effects of its deficiency, as well as to show the effects of its supplementation at different doses, different times of supplementation and routes of administration compared to placebo. The content of vitamin D3 in food products is presented in Table 1. as well as inducing cell differentiation of head and neck, breast, prostate and colorectal cancers [4]. This review aims to gather the results of studies on the biological activity of vitamin D, the effects of its deficiency, as well as to show the effects of its supplementation at different doses, different times of supplementation and routes of administration compared to placebo. The content of vitamin D3 in food products is presented 
in Table 1. as well as inducing cell differentiation of head and neck, breast, prostate and colorectal cancers [4]. This review aims to gather the results of studies on the biological activity of vitamin D, the effects of its deficiency, as well as to show the effects of its supplementation at different doses, different times of supplementation and routes of administration compared to placebo. The content of vitamin D3 in food products is presented in Table 1.

\begin{tabular}{|l|l|}
\hline Product & Vitamin D content \\
\hline feminine food & $1.5-8 \mathrm{IU} / 100 \mathrm{ml}$ \\
\hline breastfeeding with vitamin D supplementation & $20 \mathrm{IU} / 100 \mathrm{ml}$ \\
\hline initial milk & $40-56 \mathrm{IU} / 100 \mathrm{ml}$ \\
\hline next milk & \\
& $56-76 \mathrm{IU} / 100 \mathrm{ml}$ \\
\hline cow milk & $0.4-1.2 \mathrm{IU} / 100 \mathrm{ml}$ \\
\hline egg yolk & $54 \mathrm{IU} / \mathrm{yolk}$ \\
\hline cheese & $7.6-28 \mathrm{IU} / 100 \mathrm{~g}$ \\
\hline fresh eel & $1200 \mathrm{IU} / 100 \mathrm{~g}$ \\
\hline fresh wild salmon & $600-1000 \mathrm{IU} / 100 \mathrm{~g}$ \\
\hline Herring in oil & $808 \mathrm{IU} / 100 \mathrm{~g}$ \\
\hline fresh farmed salmon & $100-250 \mathrm{IU} / 100 \mathrm{~g}$ \\
\hline tuna, sardines & $200 \mathrm{IU} / 100 \mathrm{~g}$ \\
\hline mackerel & $152 \mathrm{IU} / 100 \mathrm{~g}$ \\
\hline fresh cod & $40 \mathrm{IU} / 100 \mathrm{~g}$ \\
\hline
\end{tabular}

table 1

\section{DESCRIPTION OF THE STATE OF KNOWLEDGE}

Bischoff-Ferrari and co-authors from the University of Zurich demonstrated in 2009 the effect of vitamin D3 supplementation at a dose of 700-1000 IU / day on reducing the risk of falling in people over 65 by 19 percent when reaching a serum concentration of 25hydroxycholecalciferol to $60 \mathrm{nmol} / 1$. Achieved 25- $(\mathrm{OH})$-D3 serum concentrations of 60 $\mathrm{nmol} / \mathrm{L}$ or more resulted in a decrease of $23 \%$. [6] In this way, the relationship between vitamin D3 deficiency and sarcopenia consisting in the loss of muscle mass and the associated decrease in physical fitness was confirmed, which is associated with an increased tendency to falls. [7] The effect of vitamin D3 supplementation on neuromuscular function is also confirmed by studies conducted on a group of 139 patients aged 65 years and older with a history of falls. Patients were randomly assigned to a single intramuscular injection of 600,000 and in ergocalciferol or placebo. Biochemistry, swaying posture, selection response time (CRT), total functional fitness time (AFPT) and quadriceps muscle strength were assessed. The test was carried out at the beginning of the study and 6 months after injection. AFPT worsened in the control group and improved in the study group, which is a significant difference between the two groups (+6.6 s compared with $-2.0 \mathrm{~s}, \mathrm{t}=2.80, \mathrm{p}<0.05)$. Similar changes were observed for CRT $(-0.06 \mathrm{~s}$ vs. $+0.41 \mathrm{~s}, \mathrm{t}=-2.52, \mathrm{P}<0.01)$ and swaying posture $(+0.0025$ vs. $-0.0138, \mathrm{t}=2.35, \mathrm{P}<0.02)$. Therefore, vitamin $\mathrm{D}$ has been shown to significantly affect muscle function, response time, and balance. [9] Dhesi and co-authors also showed a statistically significant difference in the reduction of posture disorders associated with neuromuscular strength disorders in the elderly by 13\%. [9] [10] Vitamin D3 supplementation also increases bone density and fracture risk as shown by the following studies. For example, 
a meta-analysis from 2002 including MEDLINE and EMBASE articles published in 19661999, 25 scientific studies in which bone density and fracture rates in women were measured for at least a year, showed a significant reduction in the risk of vertebral fractures by as much as 37\%. [8] In another study involving 2,686 people (2037 men and 649 women) aged 65-85, Trivedi, Doll and Khaw showed that supplementing 100,000 IU of oral vitamin D3 every four months can prevent fractures without side effects. In five years, 268 men and women suffered fractures, of which 147 had fractures at osteoporotic sites (hip, wrist or forearm or vertebrae). The relative risk in the vitamin $\mathrm{D}$ group compared to the placebo group was 0.78 (95\% confidence interval 0.61 to $0.99, \mathrm{P}=0.04)$ for each first fracture and $0.67(0.48$ to $0.93, \mathrm{P}=$ 0.02 ) for the hip, wrist or forearm, or for vertebral fractures. 471 participants have died. The relative risk of total mortality in the vitamin D group compared to the placebo group was 0.88. According to this study, oral supplementation of vitamin D3 at a dose of 100,000 IU every 4 months reduces the risk of first fracture by 22\%. [12] Another meta-analysis carried out in 2005, in turn, does not show that supplementation with vitamin D3 alone has a statistically significant effect on reducing the risk of hip fractures, vertebrae or any new fractures in seniors. No evidence of vitamin D analogue superiority over vitamin D alone has also been demonstrated [13]

\section{CONCLUSIONS:}

Comparing the results of different studies is not easy due to significant differences in methodology, differentiation of research groups, control of individual studies, as well as different doses, frequency and routes of vitamin D administration. The heterogeneity of studies contributed to obtaining different results of meta-analyzes. However, the vast majority showed a statistically significant, positive effect of vitamin D supplementation on the health of seniors. It should be noted that the latest research has shown that the benefits of its supplementation are not limited to strengthening teeth and bone structures, but also relate to preventing loss of balance, falls and consequent fractures. According to an analysis by Bischoff-Ferrari and co-authors, achieving a 25- $(\mathrm{OH})$-D3 serum concentration of $60 \mathrm{nmol} /$ $\mathrm{L}$ or more resulted in a decrease of $23 \%$ at a dose of 700-1000 IU per day. After reaching a concentration below 60nmol / lo 19\%. Supplementary vitamin D doses less than 700 IU may not reduce the risk of falling among older people [6]. Supplementing the deficits improves functional performance, reduces the risk of falls and accelerates recovery after rehabilitation for fractures. In addition, regular physical exercise increases these effects. [11] Vitamin D supplementation improves neuromuscular function and neuroprotective effect. In people with its deficiency, it has a significant impact on functionality, reaction time and balance, but not on muscle strength. It's a mechanism thanks to which vitamin D reduces the frequency of falls and fractures [9]. Supplementation with vitamin D3 alone is not enough for effective protection against osteoporotic bone loss and fractures. Calcium intake and modification of risk factors such as glucocorticoid use are also important. People with a high absolute risk may also need bisphosphonate, hormone replacement therapy, a selective estrogen receptor modulator or strontium.

\section{REFERENCES:}

1. Rusińska, A., Płudowski, P., Walczak, M., Borszewska-Kornacka, M. K., Bossowski, A., Chlebna-Sokół, D., ... \& Jackowska, T. (2018). Vitamin D supplementation guidelines for general population and groups at risk of Vitamin D deficiency in Poland - recommendations of the Polish society of pediatric endocrinology and diabetes and the expert panel with 
participation of national specialist consultants and representatives of scientific societies 2018 update. Frontiers in endocrinology, 9, 246.

2. Holick, M. F. (2017). The vitamin D deficiency pandemic: approaches for diagnosis, treatment and prevention. Reviews in Endocrine and Metabolic Disorders, 18(2), 153-165.

3. Jorgensen, H. L., Scholler, J., Sand, J. C., Bjuring, M., Hassager, C., \& Christiansen, C. (1996). Relation of common allelic variation at vitamin D receptor locus to bone mineral density and postmenopausal bone loss: cross sectional and longitudinal population study. Bmj, 313(7057), 586-590.

4. Zimber, A., Chedeville, A., Abita, J. P., Barbu, V., \& Gespach, C. (2000). Functional interactions between bile acids, all-trans retinoic acid, and 1, 25-dihydroxy-vitamin D3 on monocytic differentiation and myeloblastin gene down-regulation in HL60 and THP-1 human leukemia cells. Cancer research, 60(3), 672-678.

5. Czerwiński, E., \& Kumorek, A. (2012). Falls, vitamin D and fractures. Postępy Nauk Medycznych.

6. Bischoff-Ferrari, H. A., Dawson-Hughes, B., Staehelin, H. B., Orav, J. E., Stuck, A. E., Theiler, R., ... \& Henschkowski, J. (2009). Fall prevention with supplemental and active forms of vitamin D: a meta-analysis of randomised controlled trials. Bmj, 339, b3692.

7. Marcinowska-Suchowierska, E., Walicka, M., Tałałaj, M., Horst-Sikorska, W., Ignaszak-Szczepaniak, M., \& Sewerynek, E. (2010). Vitamin D supplementation in adultsguidelines. Endokrynologia Polska, 61(6), 723-729.

8. Papadimitropoulos E., Wells G., Shea B. et al.: (2002). Meta-analyzes of therapies for postmenopausal osteoporosis. VIII: Meta-analysis of the efficiency of vitamin D treatment in preventing osteoporosis in postmenopausal women. Endocr. Rev., 23: 560-569.

9. Dhesi, J. K., Jackson, S. H., Bearne, L. M., Moniz, C., Hurley, M. V., Swift, C. G., \& Allain, T. J. (2004). Vitamin D supplementation improves neuromuscular function in older people who fall. Age and ageing, 33(6), 589-595.

10. Szymański, F. M., Bomba-Opoń, D. A., Łęgosz, P., Głogowska-Szeląg, J., Baran, W., Szepietowski, J. C., ... \& Kozłowska-Wojciechowska, M. (2015). Place of vitamin D in everyday clinical practice - an interdisciplinary expert opinion. Forum Medycyny Rodzinnej 9(6): 423-434.

11. Czerwiński E., Borowy P., Kumorek A. (2012). Vitamin D and the musculoskeletal system. Stand. Med. 9: 649-654.

12. Trivedi D., Doll R., Khaw K. (2003). Effect of four monthly oral vitamin D3 (cholecalciferol) supplementation on fractures and mortality in men and women living in the community: randomized double blind controlled trial. BMJ. 1; 326(7387): 469.

13. Avenell A, Gillespie WJ, Gillespie LD, O'Connell D. (2009). Vitamin D and vitamin $\mathrm{D}$ analogues for preventing fractures associated with involutional and post-menopausal osteoporosis. Cochrane Database of Systematic Reviews, 2. Art. No.: CD000227. DOI: 10.1002/14651858.CD000227.pub3.

14. Płudowski P, Karczmarewicz E, Bayer M, Carter G, Chlebna-Sokół D et al. (2013). Practical guidelines for the supplementation of vitamin $\mathrm{D}$ and the treatment of deficits in Central Europe - recommended vitamin D intakes in the general population and groups at risk of vitamin D deficiency. Endocrinol Pol 64(4): 319+-327. DOI: 10.5603/EP.2013.0012.

15. Naeem Z. (2010). Vitamin d deficiency - An ignored epidemic. Int. J. Health Sci. 4(1): $5-6$. 